\title{
Investigating educators' implicit attitudes toward social groups
}

\author{
Jazmin Brown-Iannuzzi ${ }^{1} \&$ Sierra Bainter ${ }^{2}$ \\ ${ }^{1}$ University of Virginia \\ ${ }^{2}$ University of Miami
}

\begin{abstract}
Author Note
Research reported in this manuscript was supported by the National Study of Learning Mindsets Early Career Fellowship with funding generously provided by the Bezos Family Foundation to the Mindset Scholars Network and the University of Texas at Austin Population Research Center. The University of Texas at Austin receives core support from the National Institute of Child Health and Human Development under the award number 5R24 HD042849.

This manuscript uses data from the National Study of Learning Mindsets (doi: 10.3886/ICPSR37353.v1) (PI: D. Yeager; Co-Is: R. Crosnoe, C. Dweck, C. Muller, B.

Schneider, \& G. Walton), which was made possible through methods and data systems created by the Project for Education Research That Scales (PERTS), data collection carried out by ICF International, meetings hosted by the Mindset Scholars Network at the Center for Advanced Study in the Behavioral Sciences at Stanford University, assistance from C. Hulleman, R. Ferguson, M. Shankar, T. Brock, C. Romero, D. Paunesku, C. Macrander, T. Wilson, E. Konar, M. Weiss, E. Tipton, and A. Duckworth, and funding from the Raikes Foundation, the William T. Grant Foundation, the Spencer Foundation, the Bezos Family Foundation, the Character Lab, the Houston Endowment, the National Institutes of Health under award number R01HD08477201, the National Science Foundation under grant number 1761179, Angela Duckworth (personal gift), and the President and Dean of Humanities and Social Sciences at Stanford University. The content is solely the responsibility of the authors and does not necessarily represent the official views of the Bezos Family Foundation, the Mindset Scholars Network, the University of Texas at Austin Population Research Center, the National Institutes of Health, the National Science Foundation, or other funders.
\end{abstract}




\begin{abstract}
Given the importance of education and the role educators play on the outcomes of their students, the current research investigates implicit attitudes among a sample of mathematics educators. Implicit attitude measures are ones which investigate automatic associations between a target social group and a positive or negative feeling. These attitudes are important because they predict behaviors toward members of the target social group (e.g., Cameron, BrownIannuzzi, \& Payne, 2012; Greenwald, Poehlman, Uhlmann, \& Banaji, 2009). The current research also extends beyond previous research by investigating the association between educators' implicit racial attitudes toward black and white people and students' trust and respect for their educator. If educators' implicit attitudes are associated with how they interact with their students, it may be that we can uncover this relationship by asking students about their attitudes toward their educators. To analyze these questions, this study leverages data from the National Study of Learning Mindsets (NSLM), the largest-ever randomized controlled trial of a growth mindset program in the U.S. in K-12 settings, in which a brief online growth mindset program was administered to 9 th grade students during the 2015-2016 academic year. The results suggest that educators have a more implicit positive reaction to women than men, and slightly more implicit positivity toward black men than white men. These implicit associations, however, are unrelated to students' trust and respect for their educator. The findings and implications are discussed.
\end{abstract}




\section{Introduction}

Implicit bias has become a "hot topic" among the research and lay community alike. Since the seminal paper on implicit bias (Devine, 1989), publications on implicit bias have increased dramatically. In fact, over the last five years there have been at least 100 peer-reviewed manuscripts per year mentioning 'implicit bias' (PsycInfo, 2020). Further, organizations like Starbucks, Facebook and Google have asked all employees to complete implicit bias training. And, implicit bias was mentioned in the 2016 Presidential Debate. So, what is implicit bias? Why is implicit bias an important topic? And, why is it useful to understand implicit bias among educators?

Cognition can be thought of as operating using dual processes. Explicit processing is deliberative, controlled, and takes time and resources (such as motivation). Alternatively, implicit processing is automatic, difficult to control, and efficient (e.g., Bargh, 1994; Gawronski Bodenhausen, 2006). Implicit bias, therefore, reflects automatic responses toward one social group relative to another social group. If one of the two groups is favored, then there is evidence for implicit bias against the non-favored group. If both groups are equally favored, then there is no evidence for implicit bias. Put differently, there is evidence for implicit egalitarian attitudes.

It is important to understand implicit bias because it predicts behavior. Summaries of empirical and experimental research suggest that implicit attitudes have a modest yet significant relationship with behavior (Cameron, Brown-Iannuzzi, \& Payne, 2012; Greenwald, Poehlman, Uhlmann, \& Banaji, 2009). And, these relationships persist when controlling for the relationship between explicit attitudes and behaviors. Thus, implicit and explicit bias may uniquely predict discriminatory behaviors. 
It is important to understand the role of implicit and explicit bias among educators.

Educational attainment represents a prominent way people can attain upward economic mobility. Thus, routes which may stymie one's educational attain are important to identify and mitigate. One such impasse may be prejudice among educators. The current research investigates implicit bias among math educators.

\section{Bias among Educators}

Educators (and high school educators in particular) may represent a unique sample that is different from the majority of the U.S. adult population on several dimensions. In secondary schools, women are more likely to be educators than are men (National Center for Education Statistics, 2018). In addition, educators tend to be more educated than the general public with the majority of educators earning a postbaccalaureate degree (National Center for Education Statistics, 2018), whereas, the majority of U.S. adults have earned a high school diploma (Census, 2016). Together, these descriptive statistics suggest that compared to the U.S. population, high school educators are more educated and more likely to be women. This sample difference also has implications for prejudice. In particular, more educated individuals tend to have lower explicit and implicit bias than less educated individuals (e.g., Payne et al., 2010). Thus, we may anticipate lower levels of bias as compared to the U.S. population.

Although there may be lower levels of bias among educators as compared to the rest of the U.S. population, there exists variability in bias. That is, some educators may be more biased than other educators. Further, this difference in bias may impact students' outcomes. In particular, expectancy confirmation research suggests that instructors' expectations of students predicts students' academic outcomes (e.g., Word, Zanna \& Cooper, 1974). These expectations may be biased by racial prejudice. As a consequence, minority students tend to have worse 
academic outcomes when taught by more racially prejudiced instructors (measured both implicitly and explicitly) than when taught by less racially prejudiced instructors (e.g., Peterson, Rubie-Davies, Osborne, Sibley, 2016; Rubovits \& Maehr, 1973; Weinstein, Gregory, \& Strambler, 2004). In addition, Black students are more likely to receive harsher academic punishments (such as suspension or expulsion) in counties where implicit bias against Black people is higher (Riddle \& Sinclair, 2019). Relatedly, research finds that the ethnic gap in students' grades are explained, in part, by educators' implicit bias (van den Bergh, Denessen, Hornstra, Voeten, \& Holland, 2010). Further, experimental findings indicate that prejudiced instructors teach worse lessons when they are asked to teach a lesson for a Black (vs. White) student (Jacoby-Senghor, Sinclair, \& Shelton, 2016). These findings suggest that the race/ethnic achievement gap may be perpetuated, in part, by instructors' racial bias.

\section{Measuring Bias among Educators}

No single measure best captures bias. As described above, both implicit and explicit measures of attitudes predict behavior (e.g., Cameron, Brown-Iannuzzi, \& Payne, 2012; Greenwald, Poehlman, Uhlmann, \& Banaji, 2009). Although explicit attitude measures tend to predict behavior more strongly than do implicit attitude measures (e.g., Cameron, BrownIannuzzi, \& Payne, 2012; Greenwald, Poehlman, Uhlmann, \& Banaji, 2009), researchers also theorize that explicit and implicit attitude measures may predict different types of behavior. For example, White participants' explicit bias against Black people predicted bias in their verbal behavior when interacting with a Black (vs. White) confederate (Dovidio, Kawakami, \& Gaertner, 2002). And, White participants' implicit bias against Black people predicted nonverbal behaviors when interacting with a Black (vs. White) confederate (Dovidio, Kawakami, \& Gaertner, 2002). Further, both verbal and non-verbal behaviors predict whether Black 
participants enjoy interacting with White people (e.g., Richeson \& Shelton, 2007). Together, these findings suggest that explicit bias may predict deliberative behaviors whereas implicit bias may predict subtle, non-verbal behaviors. However, both types of behavior (verbal and nonverbal behavior) impact Black participants' attitudes about the interaction. Thus, it may be important to measure both explicit and implicit bias among educators.

In addition, it is also important to consider the influence of social desirability. Because of the nature of explicit processing - relatively slower and more deliberative than implicit processing - explicit attitudes may be shaped by social desirability concerns. In particular, when investigating attitudes about socially controversial topics, explicit attitude measures may be uniquely impacted as compared to implicit attitude measures (e.g., Nosek, 2007). Because implicit measures require people to respond quickly, these measures may circumvent social desirability concerns because people do not have time to alter their responding. For this reason, implicit measures have often been assumed to be immune to social desirability concerns and thus are frequently the desired measure when assessing socially controversial topics - such as racial and gender bias.

Although implicit bias measures may be advantageous in some respects, these measures tend to exhibit low reliability, both within a given testing session and across testing sessions (Payne \& Lundberg, 2014; Payne, Vuletich, \& Lundberg, 2017). Issues of low reliability are troubling because they inflate both type I and type II error (e.g., Cronbach, 1951; DeVellis, 2003). That is, low reliability can increase the chance of finding a significant difference when no difference exists in the population. And, low reliability can increase the chance of missing an actual different that exists in the population. As a result, it is difficult to replicate findings using measures that exhibit low reliability - a point we return to in the discussion section. 
In addition, the assumption that implicit attitude measures are immune to social desirability concerns has been challenged in recent research. For example, research suggests implicit attitudes may be flexibly changed base on the motivation of the participant or by simple experimental manipulation (e.g., Gawrsonki \& Bodenhausen, 2005; Gawronski, Hofmann, \& Wilbur, 2006). In addition, recent work suggests that people may intentionally influence their responding on certain implicit attitude measures in order to appear unbiased (e.g., Bar-Anan \& Nosek, 2012; Cummins, Hughes, \& Hussey, 2019; Cummins \& De Houwer, 2019). Other work, however, suggests that even when people intentionally try to influence their responding on certain implicit attitude measures, bias may persist (e.g., Mann et al., 2019). Together, these findings suggest that it is at least unclear whether implicit attitude measures are immune to social desirability concerns, or whether they are relatively less influenced by social desirability concerns than are explicit measures.

\section{The current research}

Overall, these findings suggest that it is important to understand educators' bias and to investigate whether this bias may be associated with students' attitudes toward their educators. The current research investigates implicit attitudes among a sample of mathematics educators. Although it may be best to use multiple measures to assess attitudes toward social groups, there are also competing concerns with respect to resources which often limit the number and type of measures which can be included in a survey. The current research utilizes one of the most reliable measures of implicit bias: The Affect Misattribution Procedure (Payne et al., 2005). In addition, the current research measures these attitudes among a diverse sample of educators - a population which is difficult to attain. 
The current research extends beyond previous research by investigating the association between educators' implicit racial attitudes toward Black and White people and students' trust and respect for their educator. If educators' implicit attitudes are associated with how they interact with their students, it may be that we can uncover this relationship by asking students about their attitudes toward their educators. To analyze these questions, this study leverages data from the National Study of Learning Mindsets (NSLM), the largest-ever randomized controlled trial of a growth mindset program in the U.S. in K-12 settings, in which a brief online growth mindset program was administered to 9th grade students during the 2015-2016 academic year. The NSLM features a nationally representative probability sample of regular U.S. public high schools. Specifically, this study analyzed mathematics educators' responses to several survey items. The sample included data from approximately 220 educators.

\section{Method}

This project uses a subset of data collected as part of a randomized-controlled trial investigating the efficacy of learning mindset interventions. This randomized-controlled trial utilized a nationally representative sample of public high schools in the United States and has followed students over the course of several years. As part of this experiment, students and educators were asked to complete survey items. To assess educators' implicit racial prejudice, we use educators' responses on the Affect Misattribution Procedure (Payne et al., 2005).

Importantly, only the students who were not part of the experimental trial were included in analyses. We describe the sample and procedure for the current analyses next.

\section{Participants.}

Educators. Because educators were not required to complete this (or any) measure, the sample of educators used in this analysis is not reflective of all educators surveyed for the 
experiment. The total number of educators which completed the main measure of interest was 252. Of these educators, 92 were men, 158 were women, and one identified as “other". In addition, 213 were White, 11 were Black, and 27 were another race/ethnicity. The average age of the sample was born in $1978(S D=10.64)$.

Students. We utilized students who did not receive the mindset intervention. Further, we only utilized students who had only one math educator, so it was clear who their responses were about. The total number of students who were not in the treatment condition and had one math educator was 2107 . Of these students, $49 \%$ were men, $51 \%$ were women. In addition, 1195 were White, 197 were Black, 502 were Hispanic, and 213 were another race/ethnicity.

\section{Procedure.}

Educators. Math educators were asked to complete a battery of surveys. Towards the end of the survey, educators were asked to complete the Affect Misattribution Procedure (AMP; Payne et al., 2005). Because this was a measure that was quite different from the other surveys in the battery, educators were given unique and specific instructions. Specifically, they were told:

"Last, we would like to ask for your help in trying out a new type of task that researchers have developed. It measures people's judgments of novel language symbols. It takes about 2 minutes. Specifically, the task measures people's attitudes about different language symbols called “pictograms.” Before each pictogram you will see real life images of people. Researchers use this task to study how people can avoid being biased. Understanding this would be an important scientific advance. Because this is a new task that differs somewhat from the rest of the survey, we wanted to give you the chance to say whether you'd like to participate. We hope you will. Many educators have said they 
liked contributing to research, and said that they found the task interesting. However, if you do not participate there is no penalty, and your choice will remain confidential."

Educators then chose to opt-in or opt-out of taking the AMP. Our analysis consists of 252 educators who took the AMP. The educators who opted-in were presented with a set of instructions which are relatively typical for the AMP. In particular, the instructions read:

"On the next page, you will see pairs of flashing images. The first image will be a real life image and the second will be a pictogram. It will be flashed quickly, so pay attention. Your task is to rate the pictogram as relatively pleasant or unpleasant, by relying on your intuition. Remember, we want people's responses to be as unbiased as possible. Please try NOT to let the real life image affect your response. Instead, try to ignore the real life image. Please don't say that all the pictograms are pleasant or that all of them are unpleasant. Try to sort them into the more pleasant half and the less pleasant half. Just respond based on your intuitions. (...) Press the spacebar to begin.” Participants then completed 160 trials of the AMP (see Figure 1 for a schematic of a single trial). Each trial began with a prime photo presented for $100 \mathrm{~ms}$. The prime photos represented eight categories: Asian men, Asian women, Black men, Black women, Hispanic men, Hispanic women, White men, and White women. The photos were taken from the Chicago Face Database (Ma, Correll, \& Wittenbrink, 2015). The prime photos were covered up by a target photo, a Chinese symbol, presented for $125 \mathrm{~ms}$. Finally, the target photo is covered up by a mask which remained on the screen until participants responded. To avoid order effects, primes and targets were randomly selected without replacement and trial order was randomly presented. 


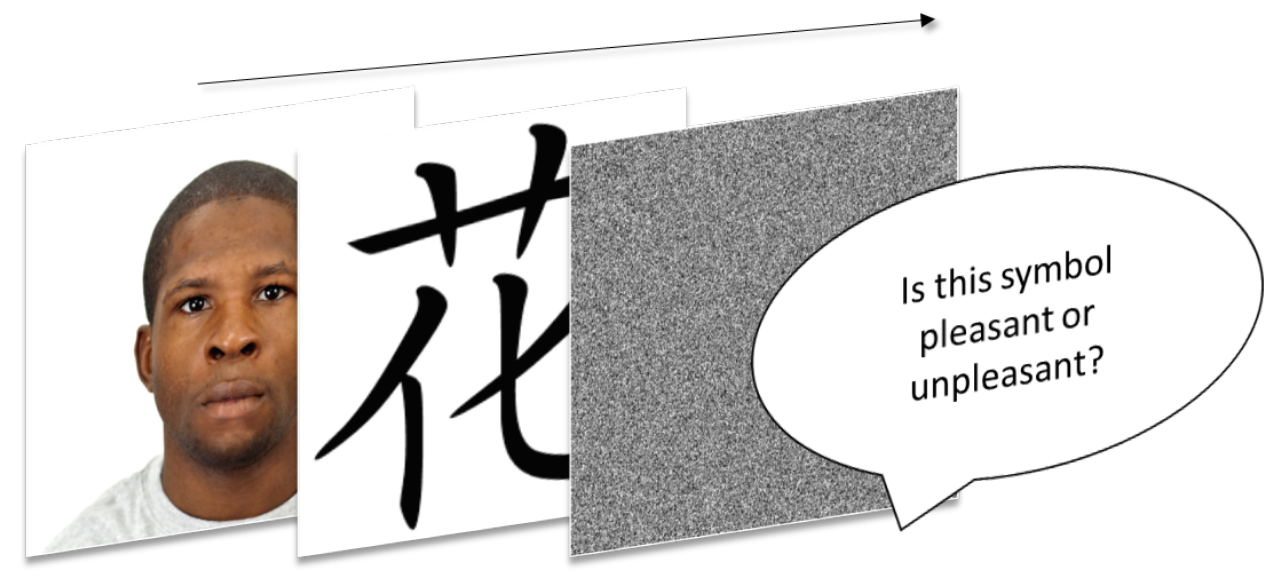

Figure 1. Schematic of an AMP trial.

For data reduction and analytic purposes, we created a proportion of pleasant responses (coded 1) for each prime category: Asian men, Asian women, Black men, Black women, Hispanic men, Hispanic women, White men, and White women. Thus, higher numbers reflect more positive attitudes toward the Chinese symbol when proceeded by a specific prime category. This proportion served as our estimate of implicit attitudes toward each race/gender category.

Students. As part of a larger survey, students responded to the following questions about their math educator: "I trust my math educator" and "My math educator treats me with respect" with response options ranging from 1 (not at all true) to 5 (extremely true).

\section{Results}

\section{Data Inspection and Descriptive Statistics}

First, we inspected the data to investigate whether anyone pressed a single type of response, such as always indicating the target symbol was pleasant or unpleasant, throughout the whole task. We found that 17 educators pressed a single type of response ( 3 always responded 'unpleasant' and 14 always responded 'pleasant'). Because the instructions explicitly asked participants to not press a single key throughout the task, we excluded these participants' data from analyses. 
Next, we investigated the distributions of responses when preceded by each prime category (Asian men, Asian women, Black men, Black women, Hispanic men, Hispanic women, White men, and White women). See Figure 2 for a graphical display of the distributions and Table 1 for descriptive statistics. The distributions were all negatively skewed and the central tendency was quite high. Although these distributions were unexpected, many of the inferential statistics we pre-registered ${ }^{1}$ are quite robust to skewed distributions, so we proceeded with our analytic plan.

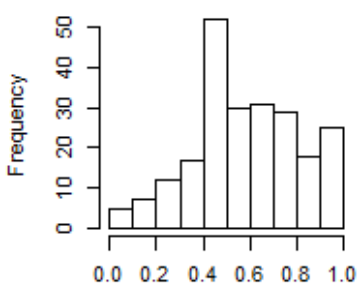

Asian Men

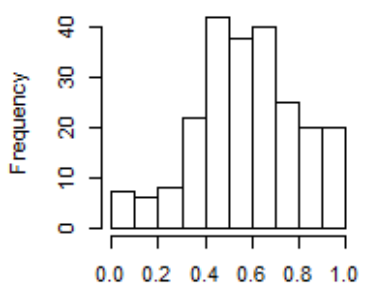

Hispanic Men

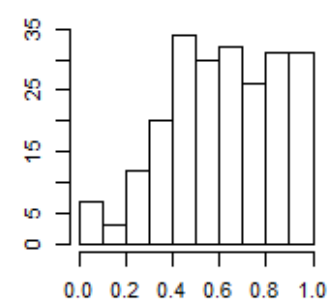

Asian Women

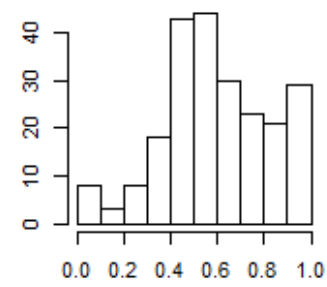

Hispanic Women

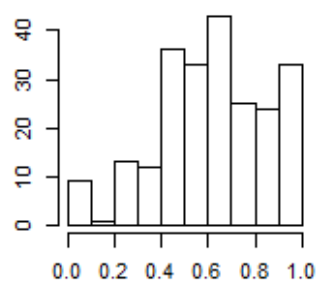

Black Men

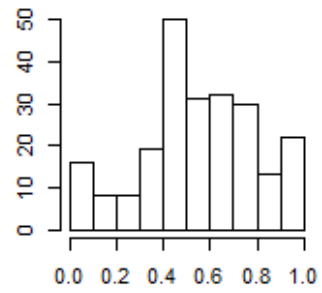

White Men

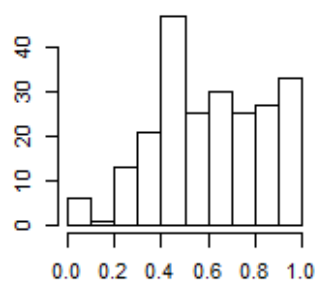

Black Women

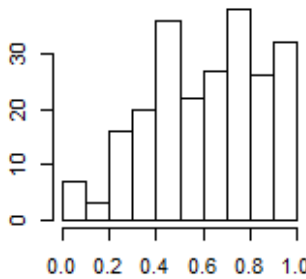

White Women

Figure 2. Graphical display of the distribution of pleasant responses toward each prime category.

\footnotetext{
${ }^{1}$ To view the pre-registration see: https://osf.io/5sgbd/
} 
Table 1.

Descriptive statistics of the proportion of pleasant responses on the AMP split by prime type.

\begin{tabular}{lcccc}
\hline & $N$ & Mean & SD & Median \\
\hline Asian men & 226 & 0.59 & 0.24 & 0.64 \\
Asian women & 226 & 0.62 & 0.22 & 0.58 \\
Black men & 228 & 0.62 & 0.23 & 0.64 \\
Black women & 229 & 0.61 & 0.23 & 0.64 \\
Latino men & 227 & 0.58 & 0.23 & 0.58 \\
Latina women & 228 & 0.61 & 0.22 & 0.58 \\
White men & 227 & 0.56 & 0.24 & 0.67 \\
White women & 229 & 0.62 & 0.24 & 0.58 \\
\hline
\end{tabular}

\section{Implicit Attitudes}

We investigated whether participants' responses toward the target symbol differed when preceded by each prime category. To investigate this question, we conducted a repeated measures ANOVA with gender as one factor (male vs. female) and race/ethnicity as another factor (Asian, Black, Latinx, and White). See Figure 3 for means and 95\% confidence intervals for each prime category. The results revealed a main effect of gender such that participants were more positive toward female primes $(M=.62, S D=.19)$ than male primes $(M=.59, S D=.17), F$ $(1,217)=9.47, p=.002$. There was not a main effect of race/ethnicity, $F(3,217)=3.78, p=$ .06 . These main effects, however, were qualified by a race/ethnicity by gender interaction, $F$ ( 3 , 217) $=3.78, p=.003$. 


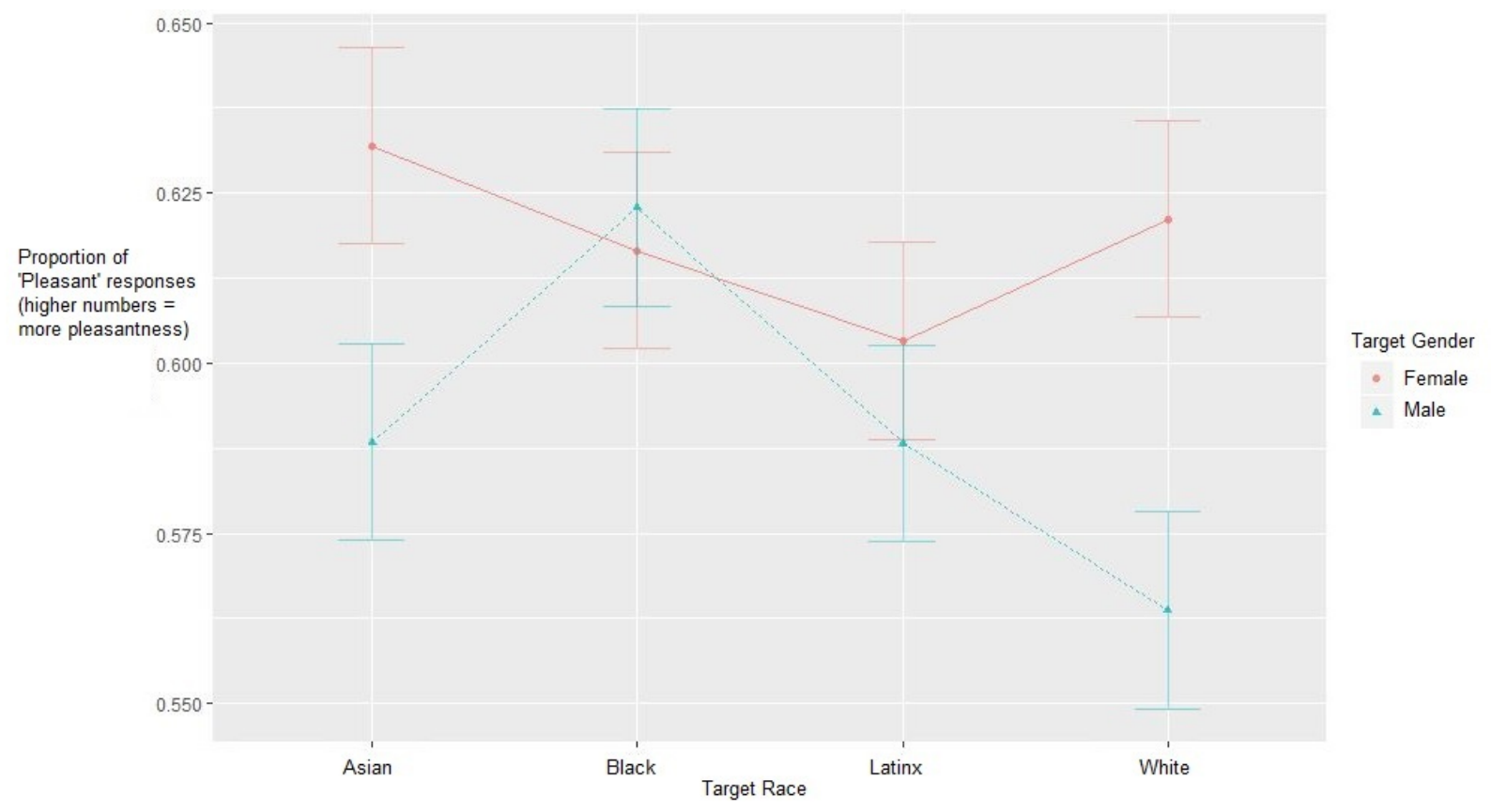

Figure 3. Means and 95\% confidence intervals for each prime category.

We probed this interaction with post-hoc analyses using a Bonferroni correction for multiple comparisons. The results revealed a significant difference between white male targets and white female targets, $M_{d i f}=0.06, p_{\text {Bonferroni }}=.008$. Participants were more positive toward white female targets than toward white male targets. In addition, there was a significant difference between white male targets and black male targets, $M_{\text {dif }}=0.06, p_{\text {Bonferroni }}=.02$. Participants were more positive toward black male targets than toward white male targets. Overall, these results are not consistent with previous research (see Payne \& Lundberg, 2014 for a review).

In addition, we investigated whether these results were moderated by educators' race/ethnicity or gender in separate analyses. Because there were very few educators who were part of underrepresented races/ethnicities $(n=38)$, we created a dummy variable which represented whether the educator was White (1) or non-White (0). In addition, we created a 
dummy variable which represented whether the educator was a man (1) or a woman (0). The findings suggest that implicit attitudes were not moderated by educators' race/ethnicity, all p's > .10. There was significant moderation by target gender and educators' gender, $F(1,216)=4.19$, $p=.004, \eta_{\mathrm{p}}^{2}=.019$. Women educators were slightly more positive toward female targets $(M=$ $0.62, S D=0.23)$ than toward male targets $(M=0.57, S D=0.23)$. However, men educators rated female targets $(M=0.62, S D=0.22)$ and male targets $(M=0.62, S D=0.20)$ similarly.

\section{Exploratory Analyses: Relationship between educators' implicit racial attitudes and}

\section{students' explicit attitudes toward their educator}

Although the implicit attitude findings were unanticipated, we investigated whether individual difference on implicit attitudes predicted students' attitudes toward their math educator. Specifically, based on previous research and theory, we anticipated that negative implicit attitudes toward Black people relative to White people would predict underrepresented racial/ethnic students' trust and respect toward their math educator. To investigate this question, we created an average of students' trust and respect toward their math educator which served as our dependent variable. Then, we created a difference score of implicit attitudes by subtracting implicit positivity toward Black primes from White primes, collapsing across the prime gender. Thus, higher numbers reflect more implicit positivity toward White people relative to Black people. We then used this variable as a level 2 predictor in a multilevel model which accounted for the fact that students were nested within educators. We also used students' race/ethnicity $(1=$ White, $0=$ non-White) as a level 1 predictor, and we calculated a cross-level interaction between educators' implicit attitudes and students' race/ethnicity. Finally, we controlled for the educators' gender and race/ethnicity and students' prior math achievement. 
With respect to predicting students' trust for their math educator, no significant effects.

See Table 1 for full results.

\begin{tabular}{lcccc}
\hline Predictor & Estimate & SE & $t$ & $p$-value \\
\hline Implicit pro-White bias & -0.05 & 0.25 & -0.18 & 0.859 \\
Student race (1 = White, 0 = non-White) & 0.00 & 0.04 & 0.07 & 0.947 \\
Implicit pro-White bias X Student race & 0.29 & 0.25 & 1.15 & 0.251 \\
Teacher race (1 = White, 0 = non-White) & -0.03 & 0.04 & -0.70 & 0.485 \\
Teacher gender (1 = man, 0 = woman) & 0.03 & 0.05 & 0.60 & 0.551 \\
Math level combined (Dummy code level 1) & -0.07 & 0.08 & -0.93 & 0.351 \\
Math level combined (Dummy code level 2) & 0.04 & 0.09 & 0.50 & 0.620 \\
Math level combined (Dummy code level 3) & 0.01 & 0.14 & 0.06 & 0.494 \\
\hline
\end{tabular}

\section{Discussion}

The data suggest that educators, on average, display more implicit positive reactions to women than men. In addition, women educators display more implicit positive reactions to women than men; whereas, male educators did not display an implicit preference for a specific gender. These finding are consistent with previously published research (e.g., Dunham, Baron \& Banaji, 2015; Rudman \& Goodwin, 2004). Inconsistent with previous research, educators, on average, displayed more implicit positive reactions to underrepresented race/ethnicities in the U.S. than to white individuals. In particular, educators reported more positivity toward black men than to white men. This is in stark contrast to previous research which finds U.S. residents tend to display more implicit positive reactions to white men than black men, or other underrepresented race/ethnicities in the U.S. (e.g., Greenwald, Poehlman, Uhlmann, \& Banaji, 2009; Payne et al., 2010; Payne \& Lundberg, 2014).

In addition, the exploratory analyses investigated the relationship between educators' implicit attitudes and their students' trust and respect for their educator. If educators' implicit attitudes are associated with how they interact with their students, it may be that we could 
uncover this relationship by asking students about their attitudes toward their educators. The results, however, suggest there is no relationship between educators' implicit attitudes and students' trust and respect of their educator.

Although there exist several plausible interpretations of these data, we detail only a few possible explanations of these data here. With respect to the implicit attitude findings, it may be that educators have little implicit bias against underrepresented racial/ethnic minority individuals, and may, at least in some situations, implicitly favor underrepresented racial/ethnic minority individuals over white individuals. As discussed above, these findings may be related to the education level of the sample. Educators, on average, are more educated than the adult U.S. population (Census, 2016; National Center for Education Statistics, 2018). More educated individuals tend to have lower explicit and implicit bias than less educated individuals (e.g., Payne et al., 2010). Thus, the implicit bias results reported here may be attributed to the relatively high education level of the sample.

Another plausible explanation for the implicit attitudes findings is that social desirability concerns may have influenced educators' responses on the implicit attitude measure (e.g., Cummins, Hughes, \& Hussey, 2019). Emerging research suggests that implicit attitude measures may not fully circumvent social desirability concerns. And, given the intrapersonal and interpersonal consequences of displaying racial/ethnic prejudice (e.g., Crandall \& Eshleman, 2003), educators' may be motivated to respond in a socially desirable manner.

A third plausible explanation is that educators' responses may reflect cognitive fatigue. The AMP was one of the last measures the educators' completed among a battery of measures. The negatively skewed distributions may be reflective of educators wanting to provide quick, "good" answers for the purpose of quickly completing a task as opposed to providing answers 
reflective of their opinions (e.g., Simon, 1956; Krosnick, 1991). Indeed, previous research suggests that educators do employ this time-saving strategy when faced with a long survey, and particularly when near the end of a long survey (Hamby \& Taylor, 2016). Unfortunately, based on the current data, we cannot distinguish which one of these possible explanations best fits the pattern of implicit attitude findings.

With respect to the exploratory analyses investigating the relationship between educators' implicit attitudes and students' trust and response for their educator, there, again, exist several possible explanations for the null results. First, it may be that regardless of the educators' implicit bias, it is not influencing their interactions with the students. Thus, there would be no relationship between educators' bias and students' attitudes toward their educator. It may also be that students are not noticing the behavioral signals of the educators' implicit bias. Third, given the relatively low reliability of implicit attitude measures (even when using the AMP) and the single-item scales used to measure students' attitudes and trust, these data may not have been adequately reliable to detect a relationship. Finally, if the implicit measure was not functioning properly, then we would not expect a relationship with students' attitudes toward their educator. Again, based on the current data, we cannot distinguish which one of these possible explanations best fits the current findings. Additional data collection and experiments may help shed light on the current findings.

\section{Conclusion}

It is important to understand educators' bias against particular social groups because this bias may be associated with students' outcomes. The current research investigated implicit attitudes among a sample of mathematics educators. The findings suggest that educators display relatively little bias, and, if anything, slightly more bias in favor women and underrepresented 
racial/ethnic minorities in the U.S. These attitudes, however, are unrelated to students' attitudes toward their educator. Future research is needed to better understand both educators' attitudes toward social groups and whether these attitudes predict students' reactions toward their educator. 


\section{References}

APA PsycInfo Journal Coverage List. (2020). Retrieved September 17, 2020, from https://www.apa.org/pubs/databases/psycinfo/coverage

Bargh, J. A. (1994). The four horsemen of automaticity: Awareness, intention, efficiency, and control in social cognition. In R. S. Wyer, Jr. \& T. K. Srull (Eds.), Handbook of social cognition: Basic processes; Applications (p. 1-40). Lawrence Erlbaum Associates, Inc.

Cameron, C. D., Brown-Iannuzzi, J. L., \& Payne, B. K. (2012). Sequential Priming Measures of Implicit Social Cognition. Personality and Social Psychology Review, 16(4), 330-350. doi: $10.1177 / 1088868312440047$

Crandall, C. S., \& Eshleman, A. (2003). A justification-suppression model of the expression and experience of prejudice. Psychological Bulletin, 129(3), 414-446. doi:10.1037/00332909.129.3.414

Cronbach, L. J. (1951). Coefficient alpha and the internal structure of tests. Psychometrika, 16(3), 297-334. doi:10.1007/bf02310555

Cummins, J., \& De Houwer, J. (2019). An inkblot for beliefs: The Truth Misattribution Procedure. Plos One, 14(6). doi:10.1371/journal.pone.0218661

Cummins, J., Hussey, I., \& Hughes, S. (2019). The AMPeror's New Clothes: Performance on the Affect Misattribution Procedure is Mainly Driven by Awareness of Influence of the Primes. doi:10.31234/osf.io/d5zn8

DeVellis, R. F. (2003). Scale development: Theory and applications. Thousand Oaks, CA: Sage Publications.

Devine, P. G. (1989). Stereotypes and prejudice: Their automatic and controlled components. Journal of Personality and Social Psychology, 56(1), 5-18. doi:10.1037/0022-3514.56.1.5

Dovidio, J. F., Kawakami, K., \& Gaertner, S. L. (2002). Implicit and explicit prejudice and interracial interaction. Journal of Personality and Social Psychology, 82(1), 62-68. doi:10.1037/0022-3514.82.1.62

Dunham, Y., Baron, A. S., \& Banaji, M. R. (2015). The development of implicit gender attitudes. Developmental Science, 19(5), 781-789. doi:10.1111/desc.12321

Ferguson, M. J., \& Bargh, J. A. (2004). Liking Is for Doing: The Effects of Goal Pursuit on Automatic Evaluation. Journal of Personality and Social Psychology, 87(5), 557-572. doi:10.1037/0022-3514.87.5.557 
Gawronski, B., \& Bodenhausen, G. V. (2005). Accessibility Effects on Implicit Social Cognition: The Role of Knowledge Activation and Retrieval Experiences. Journal of Personality and Social Psychology, 89(5), 672-685. doi:10.1037/0022-3514.89.5.672

Gawronski, B., \& Bodenhausen, G. V. (2006). Associative and propositional processes in evaluation: An integrative review of implicit and explicit attitude change. Psychological Bulletin, 132(5), 692-731. doi:10.1037/0033-2909.132.5.692

Gawronski, B., Hofmann, W., \& Wilbur, C. J. (2006). Are "implicit” attitudes unconscious? Consciousness and Cognition, 15(3), 485-499. doi:10.1016/j.concog.2005.11.007

Greenwald, A. G., Poehlman, T. A., Uhlmann, E. L., \& Banaji, M. R. (2009). Understanding and using the Implicit Association Test: III. Meta-analysis of predictive validity. Journal of Personality and Social Psychology, 97(1), 17-41. doi:10.1037/a0015575

Hamby, T., \& Taylor, W. (2016). Survey Satisficing Inflates Reliability and Validity Measures. Educational and Psychological Measurement, 76(6), 912-932. doi:10.1177/0013164415627349

Jacoby-Senghor, D. S., Sinclair, S., \& Shelton, J. N. (2016). A lesson in bias: The relationship between implicit racial bias and performance in pedagogical contexts. Journal of Experimental Social Psychology, 63, 50-55. doi:10.1016/j.jesp.2015.10.010

Krosnick, J. A. (1991). Response strategies for coping with the cognitive demands of attitude measures in surveys. Applied Cognitive Psychology, 5(3), 213-236. doi:10.1002/acp.2350050305

Ma, D. S., Correll, J., \& Wittenbrink, B. (2015). The Chicago face database: A free stimulus set of faces and norming data. Behavior Research Methods, 47(4), 1122-1135. doi:10.3758/s13428-014-0532-5

Mann, T. C., Cone, J., Heggeseth, B., \& Ferguson, M. J. (2019). Updating implicit impressions: New evidence on intentionality and the affect misattribution procedure. Journal of Personality and Social Psychology, 116(3), 349-374. doi:10.1037/pspa0000146

National Center for Education Statistics. (2020). Characteristics of Public School Teachers. Retrieved September 17, 2020, from https://nces.ed.gov/programs/coe/indicator_clr.asp

Nosek, B. A. (2007). Implicit-Explicit Relations. Current Directions in Psychological Science, 16(2), 65-69. doi:10.1111/j.1467-8721.2007.00477.x

Nosek, B. A., \& Bar-Anan, Y. (2012). Scientific Utopia: I. Opening Scientific Communication. Psychological Inquiry, 23(3), 217-243. doi:10.1080/1047840x.2012.692215 
Payne, B. K., Cheng, C. M., Govorun, O., \& Stewart, B. D. (2005). An inkblot for attitudes: Affect misattribution as implicit measurement. Journal of Personality and Social Psychology, 89(3), 277-293. doi:10.1037/0022-3514.89.3.277

Payne, B. K., Krosnick, J. A., Pasek, J., Lelkes, Y., Akhtar, O., \& Tompson, T. (2010). Implicit and explicit prejudice in the 2008 American presidential election. Journal of Experimental Social Psychology, 46(2), 367-374. https://doi.org/10.1016/j.jesp.2009.11.001

Payne, B. K., Vuletich, H. A., \& Lundberg, K. B. (2017). The Bias of Crowds: How Implicit Bias Bridges Personal and Systemic Prejudice. Psychological Inquiry, 28(4), 233-248. doi:10.1080/1047840x.2017.1335568

Payne, K., \& Lundberg, K. (2014). The Affect Misattribution Procedure: Ten Years of Evidence on Reliability, Validity, and Mechanisms. Social and Personality Psychology Compass, 8(12), 672-686. doi:10.1111/spc3.12148

Peterson, E., Rubie-Davies, C., Osborne, D., \& Sibley, C. (2016). Teachers' explicit expectations and implicit prejudiced attitudes to educational achievement: Relations with student achievement and the ethnic achievement gap. Learning and Instruction, 42, 123-140. doi:10.1016/j.learninstruc.2016.01.010

Richeson, J. A., \& Shelton, J. N. (2007). Negotiating Interracial Interactions. Current Directions in Psychological Science, 16(6), 316-320. doi:10.1111/j.1467-8721.2007.00528.x

Riddle, T., \& Sinclair, S. (2019). Racial disparities in school-based disciplinary actions are associated with county-level rates of racial bias. Proceedings of the National Academy of Sciences, 116(17), 8255-8260. doi:10.1073/pnas.1808307116

Rubovits, P. C., \& Maehr, M. L. (1973). Pygmalion black and white. Journal of Personality and Social Psychology, 25(2), 210-218. doi:10.1037/h0034080

Rudman, L. A., \& Goodwin, S. A. (2004). Gender Differences in Automatic In-Group Bias: Why Do Women Like Women More Than Men Like Men? Journal of Personality and Social Psychology, 87(4), 494-509. doi:10.1037/0022-3514.87.4.494

Simon, H. A. (1956). Rational choice and the structure of the environment. Psychological Review, 63(2), 129-138. doi:10.1037/h0042769

US Census Bureau. (2018). Highest Educational Levels Reached by Adults in the U.S. Since 1940. Retrieved September 17, 2020, from https://www.census.gov/newsroom/pressreleases/2017/cb17-51.html

Van Den Bergh, L., Denessen, E., Hornstra, L., Voeten, M., \& Holland, R. W. (2010). The Implicit Prejudiced Attitudes of Teachers. American Educational Research Journal, 47(2), 497-527. doi:10.3102/0002831209353594 
Weinstein, R. S., Gregory, A., \& Strambler, M. J. (2004). Intractable Self-Fulfilling Prophecies Fifty Years After Brown v. Board of Education. American Psychologist, 59(6), 511-520. doi:10.1037/0003-066x.59.6.511

Word, C. O., Zanna, M. P., \& Cooper, J. (1974). The nonverbal mediation of self-fulfilling prophecies in interracial interaction. Journal of Experimental Social Psychology, 10(2), 109-120. doi:10.1016/0022-1031(74)90059-6 